\title{
A systematic evaluation of network protection responses in future converter-dominated power systems
}

\author{
Ruiqi Li*, Campbell Booth*, Adam Dyśko*, Andrew Roscoe*, Helge Urdal ${ }^{\dagger}$, Jiebei Zhu* \\ * Department of Electronic and Electrical Engineering, University of Strathclyde, Glasgow, G1 1XW, UK. contact: \\ \{ruiqi.li, campbell.d.booth, a.dysko, andrew.j.roscoe\}@strath.ac.uk \\ †Urdal Power Solutions Ltd. contact: helge@urdalpowersolutions.com \\ * Network Strategy Group, National Grid, Warwick, CV34 6DA, UK. contact: jiebei.zhu@nationalgrid.com
}

Keywords: power system protection, power electronics, renewable power integration, system modelling, protection testing

\begin{abstract}
This paper illustrates how converter interfaces, used to connect renewable energy sources, HVDC links and infeeds to the power system, may bring significant changes to the behaviour of protection systems in the future. A converter model, capable of providing adjustable fault responses, is used to investigate the response of power system protection to a range of fault conditions. Different scenarios have been simulated by applying different types of faults at different location of the transmission system with a variety of different converter response types. A dynamic, verified, relay model and a hardware relay device have been injected with the simulated results to ascertain network protection performance.
\end{abstract}

A summary of results are presented and it is shown that, when the system is dominated by converter-interfaced sources (especially where the sources are modeled as being unable to provide "fast" and "high" fault currents), the responses of traditional protection systems could be delayed, lose discrimination, e.g. by tripping with a zone 2 delay for a zone 1 fault, or may be completely unable to detect faults at certain locations within the system. The outcomes of the paper and further work should act as a guide for on-going investigations and assist in informing the specification of national grid codes and related work.

\section{Introduction}

The utilisation of converter-interfaced energy sources (e.g. in HVDC infeeds, wind, solar, etc.) is increasing significantly, particularly in the GB system, due to decarbonisation and an increase in the use of HVDC interconnectors. According to National Grid's 'UK Future scenarios' document [1], renewable technologies may contribute an overall average of $34 \%$ of electricity supplied by 2020 . The peak for renewable energy penetration could of course be significantly higher than this average value [2].
Converter-interfaced sources behave very differently from traditional directly-connected rotating synchronous generators, and this will have consequences such as reduced and variable fault levels, and possibly higher levels of distortion in current and voltage waveforms during faults. Converters could also potentially lead to relatively slower responses of power system protection to short circuits due to delays in the delivery of fault current from converter-interfaced arising from converter controller actions. Concerns have been raised publicly by National Grid relating to the fact that converter-interfaced sources may lead to issues with fault discrimination and detection using traditional network protection methods [3].

As the fault response of converters is directly influenced by the control systems within the converter itself (and the capability of the energy source "behind" the converter), there is presently no universally-accepted or understood form of a typical converter current (and voltage) output during fault conditions. The European "Network Code on Requirements for Grid Connection applicable to all Generators" [4] and the "Network Code on HVDC Connections and DC-connected Power Park Modules" [5] published by ENTSO-E, have stated that generating units (regardless of interfacing technology) should be capable of providing "fast" symmetrical fault current during a symmetrical network fault, and if required, produce asymmetrical currents during unbalanced fault conditions. However, the requirements are somewhat non-specific in many instances, with the details of the exact specifications being left to national operators to define. Accordingly, it is important to investigate systematically the impact upon protection systems of a range of credible converter outputs during faults.

In order to implement an accurate and flexible representation of a converter source for use in protection studies, a comprehensive Voltage Source Converter (VSC) model has been developed [6]. The model has been further refined [7] to allow the user to modify its responses during fault conditions. Using this converter model, an initial range of injection tests (into both modelled and actual relay devices) was reported in [8] and it was confirmed that there could be problems with network protection responses in certain circumstances. In this paper, a more systematic evaluation of the protection responses and identifications of particular areas of concern are reported. 
The main body of the paper will present the development of a VSC model, with an appropriate controller, capable of reproducing realistic and user-configurable voltages and currents in response to faults on the supplied AC power system. The results of systematic tests of network protection performance under a variety of situations will be presented. This includes different fault locations and different fault types (three-phase, phase-phase and phase-earth). For each scenario, a range of adjustments to the converter controller parameters are made to change its response and the consequent protection behavior is analysed, illustrating how protection performance might be impacted by different converter responses. The testing of the system protection performance is performed through injecting simulated data into a relay model and an actual relay device using an RTDS (real time digital simulator) and APTS (automatic protection test set) for amplification of the RTDS output signals.

\section{Converter fault responses}

Converters will provide relatively limited fault current contributions when compared with a synchronous machine of comparable rated capacity. Synchronous machines may provide fault currents of 5-7 times larger than rated current immediately following close-up short circuits. However, the fault current provided by a converter-interfaced source may only be 1-2 times rated current [9] [10], and in some cases, under severe voltage depressions, some converters may not even be capable of providing rated current [11].

The fault response is defined by the converter's control system and is also guided, at least at a high-level, by appropriate grid codes. Converters may not be capable of providing large fault current instantaneously - the converter source may only provide fault current after an initial delay and then ramp up to its maximum output [12].

Finally, it should be noted that grid codes requirements are still under development. As stated in the most up-to-date GB and EU grid codes [4] [5] [13], converter-interfaced units should produce "fast", "maximum" and "sustainable" current in response to network faults and should also be capable of supplying unbalanced currents if required). However, some of the definitions are rather non-specific in nature and are open to interpretation. Discussions relating to converter responses during the period immediately following fault inception and when the network protection would be required to detect and react to faults are discussed in [12], but it is the opinion of the authors that the overall debate is still at a relatively early stage.

\section{Test system arrangement}

\subsection{VSC-HVDC model}

Figure 1 illustrates the control scheme used within the converter model, while the converter's fault response characteristics, and how they may be modified, are displayed in Figure 2. The output from the converter is governed by its current controller in response to the measured terminal voltage. The value of the current is calculated using an outer controller. The detailed operating principles of this model are explained in more detail in [6].

Fault detection, fault ride through and fault response blocks (as part of the outer controller in Figure 1) are incorporated within the control system in order to allow the converter to provide performance that complies with grid codes. The detailed logic schemes can be found in [7].

As shown in Figure 2, there are a number of configurable converter fault response settings:

- Response delay: the time taken for the converter's controller to detect faults, process the measurements and initiate the response (there may be an initial "spike" due to capacitive discharge, this is not included as a configurable parameter).

- Ramp rate limit: this can be used to reflect different converters' ability to increase their output, if indeed the output does increase [11].

- Fault level: the maximum sustained fault current output.

- Current dip: as shown by others [11] via experiments, the current output from the converter may experience an initial temporary "dip" in output immediately following a fault.

Consequently this converter model is capable of reproducing virtually any type of fault response that may be produced in reality through configuration of its parameters. For example, a "strong" converter, with relatively fast detection, high ramp rate and high sustained fault current, or a "weak" converter, with relatively slow detection, ramp rates and low sustained fault currents, could be created through appropriate configuration of the parameters. The ranges of parameters used in these investigation are from 2-200 ms for detection, 0.1-1.5 GVA/cycle for ramp rate and 1.1-2.6 GVA for fault level (for a 1.1 GVA rated converter).

\subsection{Power system layout}

The layout of the studied power system is presented in Figure 3. Using ten year statement data, a section of the $400 \mathrm{kV}$ transmission system has been modelled. The nominal power flow for the transmission line under study is $1066 \mathrm{MVA}$. The fault level of the system is assumed to be $20 \mathrm{GVA}$ when it is supplied by traditional synchronous sources [3].

When faults are applied in this system, the voltage and current value at the bus on the left-hand side of the figure above are recorded for model/relay injection. The setting of the relays (distance relays in this case) have been provided by National Grid. 


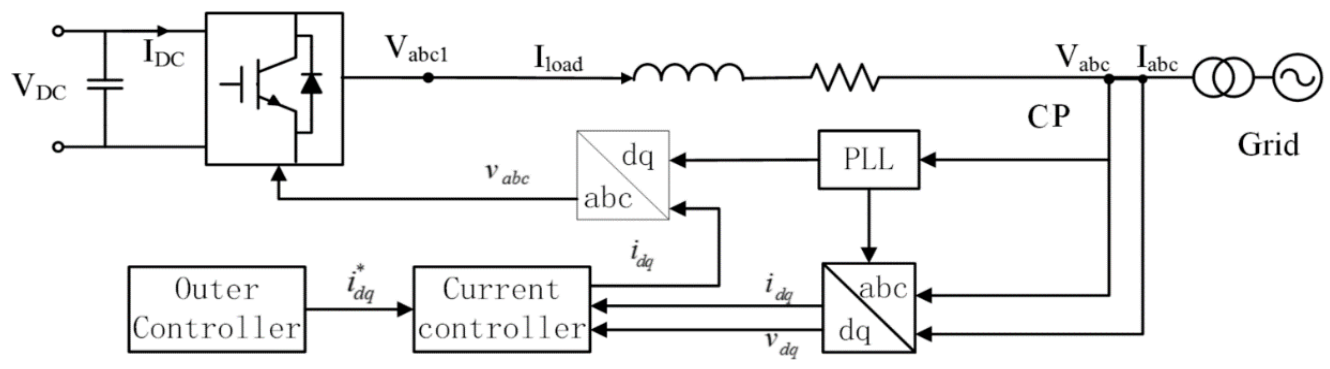

Figure 1 Layout of the VSC-HVDC model

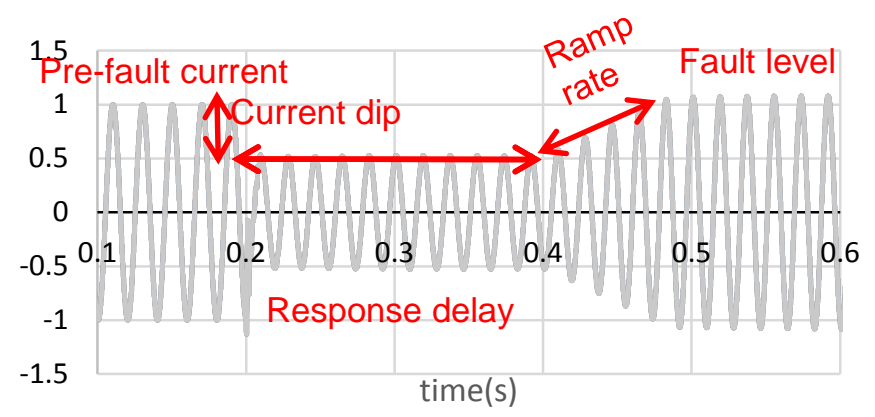

Figure 2 Controllable output current provided by converter (single phase in pu value)

\section{Case studies}

The simulated results for a variety of fault scenarios have been recorded and injected into both a validated dynamic model of a relay (relay 1) [14] and an actual distance protection relay (relay 2). The setting for both "relays" are identical.

Firstly, for three fixed fault locations $(5 \%, 50 \%$ and $100 \%$ of the line length), various parameters of the converter response characteristics were modified and several tests conducted. Scenarios 1, 2 and 3 analyse responses for three-phase, phasephase and phase-earth faults at the three locations. Secondly, the converter parameters were adjusted to represent "strong" and "weak" converters and faults at different locations along the line and specifically around the zone 1 boundary were simulated to test the reach of the relay. Scenarios 4, 5 and 6 show these results, for three-phase, phase-phase and phaseearth faults, with results for synchronous machine, "strong", and "weak" converter infeeds shown for comparison purposes. Note that while in practice, the fault current will be supplied by a "mix" of synchronous and converter-interfaced sources, in this paper the "worst-case" scenarios are investigated, where purely converter-interfaced sources supply fault current.

\subsection{Scenario 1: protection responses to three-phase faults}

The purpose of this scenario is to investigate the effect of changing converter behaviour in terms of initial response delay, current ramp rates and fault level, when the system experiences a solid three-phase fault at three different locations. The relay (model and actual device) tripping times are shown in Table 1. Two different energy sources are

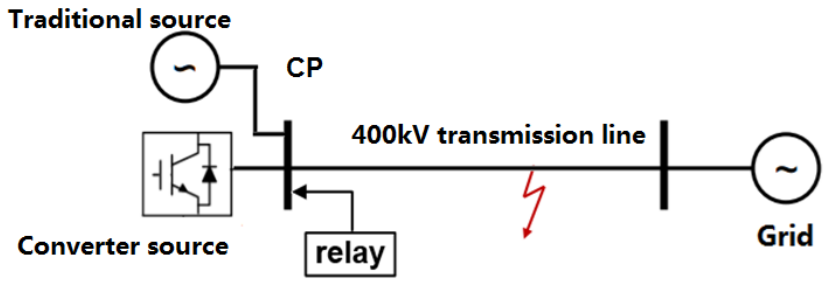

Figure 3 Model of a transmission line used in the study

included in the tests: SG - synchronous machine (case 1.1); and VSC - converter-interfaced source (cases 1.2-1.15).

$T_{\text {trip } 1}$ and $T_{\text {trip } 2}$ correspond to relay 1 (modelled) and 2 (actual device) tripping times. Note that these are not clearance times, which would be subject to an additional delay associated with circuit breaker opening.

Analysis of the results presented in Table 1 leads to the following observations:

For zone 1 three-phase faults located at $5 \%$ of the line length, a delay in the converter initial response or a reduction in fault level can lead to delayed protection responses for both relay model and device. Relay 1 responds to a close-up fault as a zone 2 fault, with its tripping time being longer than $300 \mathrm{~ms}$ when the system is supplied by converters which are unable to provide fast and/or high fault current. Relay 2 may not trip if the converter's fault level falls below 1.9 GVA.

- For three-phase faults at 50\% distance of the line: the setting for the converter will lead to delayed protection response (for both relay 1 and 2). However relay 1 trips quickly and not with a zone 2 delay. Relay 2 may not trip if the converter's fault level is decreased to less than 1.55 GVA.

- For zone 2 three-phase faults (faults at $100 \%$ of the line length), varying the characteristics of converter's fault response appear to have less of an effect on protection performance. However, relay 2 may not trip if the converter's fault level is reduced below 1.9 GVA. 
Table 1: Relay tripping times for three-phase faults

\begin{tabular}{|c|c|c|c|c|c|c|c|c|c|c|}
\hline \multirow{3}{*}{$\begin{array}{l}\text { Case } \\
\text { Number }\end{array}$} & \multirow{3}{*}{$\begin{array}{l}\text { Energy } \\
\text { source }\end{array}$} & \multirow{3}{*}{$\begin{array}{l}\text { Initial } \\
\text { delay } \\
(\mathrm{ms})\end{array}$} & \multirow{3}{*}{$\begin{array}{l}\text { Ramp } \\
\text { rate } \\
\text { (GVA } \\
\text { /cycle) }\end{array}$} & \multirow{3}{*}{$\begin{array}{l}\text { Fault } \\
\text { level } \\
(\mathrm{GVA})\end{array}$} & \multicolumn{6}{|c|}{ Fault location } \\
\hline & & & & & \multicolumn{2}{|c|}{$5 \%$} & \multicolumn{2}{|c|}{$50 \%$} & \multicolumn{2}{|c|}{$100 \%$} \\
\hline & & & & & $\begin{array}{l}T_{\text {tripl }} \\
\text { (ms) }\end{array}$ & $\begin{array}{l}T_{\text {trip } 2} \\
(\mathrm{~ms})\end{array}$ & $\begin{array}{l}T_{\text {tripl }} \\
(\mathrm{ms})\end{array}$ & $\begin{array}{l}T_{\text {trip } 2} \\
(\mathrm{~ms})\end{array}$ & $\begin{array}{l}T_{\text {tripl }} \\
(\mathrm{ms})\end{array}$ & $\begin{array}{l}T_{\text {trip } 2} \\
\text { (ms) }\end{array}$ \\
\hline 1.1 & SG & NA & NA & 20 & 41.5 & 18.2 & 19.7 & 22.8 & 330.7 & 320.8 \\
\hline 1.2 & VSC & 2 & 1.5 & 2.6 & 20.5 & 25 & 33.8 & 35 & 334.3 & 329 \\
\hline 1.3 & VSC & 200 & 0.1 & 1.1 & 140.3 & 35.4 & 98.9 & 88 & 339.8 & 329.7 \\
\hline 1.4 & VSC & 25 & 1.5 & 2.6 & 349.4 & 31.3 & 88.9 & 31 & 358.2 & 348.6 \\
\hline 1.5 & VSC & 50 & 1.5 & 2.6 & 128.2 & 33.8 & 98.9 & 34 & 352.7 & 330.3 \\
\hline 1.6 & VSC & 75 & 1.5 & 2.6 & 131.2 & 34 & 98.9 & 55 & 352.7 & 331.8 \\
\hline 1.7 & VSC & 100 & 1.5 & 2.6 & 128.4 & 35.5 & 98.9 & 56 & 352.7 & 332.9 \\
\hline 1.8 & VSC & 2 & 1.15 & 2.6 & 21 & 29.6 & 67.2 & 28 & 333.3 & 326.7 \\
\hline 1.9 & VSC & 2 & 0.8 & 2.6 & 20.7 & 24.1 & 36 & 30 & 333.2 & 327.8 \\
\hline 1.10 & VSC & 2 & 0.45 & 2.6 & 20.5 & 26 & 34.2 & 24 & 336.2 & 328.2 \\
\hline 1.11 & VSC & 2 & 0.1 & 2.6 & 349.4 & 28.2 & 34.1 & 30 & 336.5 & 324.9 \\
\hline 1.12 & VSC & 2 & 1.5 & 2.25 & 20.5 & 24.5 & 33.8 & 32 & 336.4 & 329.9 \\
\hline 1.13 & VSC & 2 & 1.5 & 1.9 & 20.5 & 25 & 33.7 & 34 & 336.3 & 329.4 \\
\hline 1.14 & VSC & 2 & 1.5 & 1.55 & 20.5 & $\infty$ & 43.6 & $\infty$ & 336.4 & $\infty$ \\
\hline 1.15 & VSC & 2 & 1.5 & 1.2 & 349.4 & $\infty$ & 43.5 & $\infty$ & 345.4 & $\infty$ \\
\hline
\end{tabular}

\subsection{Scenario 2: protection responses to phase-phase faults}

In this scenario the effects of changing the converter's fault response characteristics are investigated when the system experiences solid phase-phase faults. The relay tripping times are recorded in Table 2 . Note that the source parameters assumed for cases 2.1 to 2.15 are the same as those previously defined in Table 1. This also applies to all cases presented in section 4.3.

Table 2: Relay tripping times for phase-phase faults

\begin{tabular}{|l|c|c|c|c|c|c|}
\hline \multirow{2}{*}{ Case } & \multicolumn{6}{|c|}{ Fault location } \\
\cline { 2 - 7 } & \multicolumn{2}{|c|}{$5 \%$} & \multicolumn{2}{c|}{$50 \%$} & \multicolumn{2}{c|}{$100 \%$} \\
\cline { 2 - 7 } & $\begin{array}{c}T_{\text {trip } 1} \\
(\mathrm{~ms})\end{array}$ & $\begin{array}{c}T_{\text {trip } 2} \\
(\mathrm{~ms})\end{array}$ & $\begin{array}{c}T_{\text {trip }} \\
(\mathrm{ms})\end{array}$ & $\begin{array}{c}T_{\text {trip } 2} \\
(\mathrm{~ms})\end{array}$ & $\begin{array}{c}T_{\text {trip1 }} \\
(\mathrm{ms})\end{array}$ & $\begin{array}{c}T_{\text {trip } 2} \\
(\mathrm{~ms})\end{array}$ \\
\hline 2.1 & 19.7 & 17 & 19.7 & 25.2 & 319.6 & 324.5 \\
\hline 2.2 & 48.5 & 30.5 & 58.5 & 21.2 & 332.4 & 331.8 \\
\hline 2.3 & $\infty$ & 343.3 & $\infty$ & 121.3 & $\infty$ & 712.2 \\
\hline 2.4 & $\infty$ & 38.1 & $\infty$ & 52 & $\infty$ & 663 \\
\hline 2.5 & $\infty$ & 344.4 & $\infty$ & 120 & $\infty$ & 687.5 \\
\hline 2.6 & $\infty$ & 345.1 & $\infty$ & 129 & $\infty$ & 675.4 \\
\hline 2.7 & $\infty$ & 325.2 & $\infty$ & 126 & $\infty$ & 746.9 \\
\hline 2.8 & 43.2 & 28.8 & 87.2 & 47 & 339.6 & 347.3 \\
\hline 2.9 & 48.6 & 28.9 & 48.5 & 29 & 348.4 & 356.1 \\
\hline 2.10 & 48.5 & 30.8 & 45.7 & 30.1 & 357.4 & 330.7 \\
\hline 2.11 & 42.3 & 31 & 77.4 & 31.9 & 366.5 & 369.4 \\
\hline 2.12 & 59.2 & 31 & 43.4 & 29 & 348.6 & 334.9 \\
\hline 2.13 & 42.2 & 29.5 & 42.2 & 29 & 332.3 & 332.2 \\
\hline 2.14 & 42.2 & $\infty$ & 42.2 & $\infty$ & 342.2 & $\infty$ \\
\hline 2.15 & $\infty$ & $\infty$ & $\infty$ & $\infty$ & $\infty$ & $\infty$ \\
\hline
\end{tabular}

The key findings from these results can be summarised as follows:

- For zone 1 faults located at $5 \%$ of the length of the line, the characteristics of the converter may lead to inoperation of both relays when the delay is long and/or the fault level is low. For relay 2, when the converter's fault current output delay is longer than $50 \mathrm{~ms}$, the relay responds as if a zone 2 fault, rather than a zone 1 fault, has been detected.

- For zone 1 faults located at $50 \%$ of the line length, the relay's performance can be seriously affected by the converters. When the converter's fault level is decreased to a certain value (approximately 1.2 GVA for relay 1 and 1.55 GVA for relay 2) the relays no longer detect the presence of the fault and do not respond. For relay 1, when the response delay is increased to above $25 \mathrm{~ms}$, the fault is not detected.

- For zone 2 faults located at $100 \%$ of the line length, certain converter characteristics (long delays or low fault levels) may lead to inoperation of both relays (model and device).

\subsection{Scenario 3: protection responses to phase-earth faults}

Protection operating times in response to solid phase-earth faults are presented in Table 3. The key findings observations are:

- For zone 1 faults located at 5\% of the line length, the converter source does not seem to have a significant effect on the performance of relay 1 , regardless of the converter fault response characteristics. However, the performance of relay 2 is seriously affected. Relay 2 does not detect the fault under the majority of cases. This is likely to be due to the symmetrical response of the converter to single 
phase-to-earth faults which may block the relay's phaseto-earth comparators.

- $\quad$ For faults located at $50 \%$ of the line length, again relay 1 is not affected by the introduction of the converters. However for relay 2, the introduction of the converter seriouly affects the relay's operation: the tripping time is seriouly delayed, and the relay is unable to detect faults when the converter's fault current is not fast/high.

- For zone 2 faults located at $100 \%$ of the line length, it can be seen that the operation of both relays is seriously affected. When the converter generates a fast balanced fault current during faults, neither of the relays can detect the fault. It is only when the converter fault current is delayed and has limited magnitude that relay 1 can detect faults while relay 2 still remains inoperative.

Table 3: Relay tripping times for phase-earth faults

\begin{tabular}{|l|l|c|c|c|c|c|}
\hline \multirow{3}{*}{ Case } & \multicolumn{7}{|c|}{ Fault location } \\
\cline { 2 - 7 } & \multicolumn{2}{|c|}{$5 \%$} & \multicolumn{2}{|c|}{$50 \%$} & \multicolumn{2}{c|}{$100 \%$} \\
\cline { 2 - 7 } & $\begin{array}{l}T_{\text {trip } 1} \\
(\mathrm{~ms})\end{array}$ & $\begin{array}{c}T_{\text {trip } 2} \\
(\mathrm{~ms})\end{array}$ & $\begin{array}{c}T_{\text {trip } 1} \\
(\mathrm{~ms})\end{array}$ & $\begin{array}{c}T_{\text {trip } 2} \\
(\mathrm{~ms})\end{array}$ & $\begin{array}{c}T_{\text {trip } 1} \\
(\mathrm{~ms})\end{array}$ & $\begin{array}{c}T_{\text {trip } 2} \\
(\mathrm{~ms})\end{array}$ \\
\hline 3.1 & 19.5 & 16.4 & 34 & 19.2 & 323.3 & 315.6 \\
\hline 3.2 & 25.6 & $\infty$ & 25.6 & 542.6 & $\infty$ & $\infty$ \\
\hline 3.3 & 22 & $\infty$ & 25.5 & $\infty$ & 348 & $\infty$ \\
\hline 3.4 & 22 & $\infty$ & 25.5 & $\infty$ & 346.7 & $\infty$ \\
\hline 3.5 & 22 & $\infty$ & 25.5 & $\infty$ & 348 & $\infty$ \\
\hline 3.6 & 22 & $\infty$ & 25.5 & $\infty$ & 348 & $\infty$ \\
\hline 3.7 & 22 & $\infty$ & 25.5 & $\infty$ & 348 & $\infty$ \\
\hline 3.8 & 25 & $\infty$ & 25.5 & 50.2 & 349.5 & $\infty$ \\
\hline 3.9 & 25.6 & $\infty$ & 25.5 & 633 & $\infty$ & $\infty$ \\
\hline 3.10 & 22.1 & $\infty$ & 25.6 & 645.7 & $\infty$ & $\infty$ \\
\hline 3.11 & 22.1 & $\infty$ & 25.6 & 733.6 & 360.3 & $\infty$ \\
\hline 3.12 & 25.6 & $\infty$ & 25.6 & $\infty$ & 366.7 & $\infty$ \\
\hline 3.13 & 25.3 & $\infty$ & 25.3 & $\infty$ & 735.2 & $\infty$ \\
\hline 3.14 & 25.5 & $\infty$ & 25.4 & $\infty$ & 320.4 & $\infty$ \\
\hline 3.15 & 22.1 & $\infty$ & 22.2 & $\infty$ & 320.1 & $\infty$ \\
\hline
\end{tabular}

\subsection{Scenario 4: zone 1 reach tests for three-phase solid faults}

In this scenario, three different sources (SG and converters) were modelled, with three-phase solid faults applied at different locations along the line around the zone boundary at $80 \%$ of the line length. The following sources were incorporated in this scenario:

- SG: conventional synchronous machine with fault level of $20 \mathrm{GVA}$.

- VSC1: "strong" VSC with initial response delay of $2 \mathrm{~ms}$, ramp rate of $1.5 \mathrm{GVA} / \mathrm{cycle}$, and sustained fault level of 2.6 GVA (balanced output current).

- VSC2: "weak", slower-acting VSC, with initial response delay of $200 \mathrm{~ms}$, ramp rate of $0.1 \mathrm{GVA} /$ cycle, and sustained fault level of 1.1GVA (balanced output current).
The corresponding relay tripping times against distance to fault are plotted in Figures 4(a) and 4(b). It is clear from the results that the response characteristics of the converter may significantly affect the reach of zone 1 . For both relays, zone 1 reach is at around $80 \%$ of the line when the fault current is supplied by synchronous machines, as would be expected. When the system is supplied by VSC1 (with a "strong" response), the zone 1 reach is slightly extended. However, with the "weak" VSC2 supplying the fault current, zone 1 reach is significantly extended for relay 1 (to $95 \%$ of the line length) while it is reduced for relay 2 (to $76 \%$ ). These results demonstrate that the effects of converter fault response can differ for different relay types, although in this case one "relay" is modelled and one is an actual device - further work will be concerned with evaluating the responses of a wider range of relay types and devices, including distance, differential and overcurrent.

\subsection{Scenario 5: zone 1 reach tests for phase-phase solid faults}

In this scenario, phase-phase faults were applied at different locations along the line and around the zone boundary with the same assumptions and modelled converter characteristics as described in the previous section. The corresponding relay tripping times against distance to fault are plotted in Figures 4(c) and 4(d).

For relay 1, application of the "weak" converter source VSC2 leads to lack of operation regardless of fault location. However for the "strong" VSC1 source, zone 1 reach remain accurate at around $80 \%$.

For relay 2 the application of "weak" VSC2 appears to introduce a constant delay to the zone 1 operation of the relay. Furthermore, when the fault location reaches $95 \%$ of the line length, the relay stops detecting the fault altogether.

\subsection{Scenario 6: zone 1 reach tests for phase-earth solid faults}

In this scenario, phase-earth faults were applied at different locations along the line and around the zone boundary with the same assumptions and modelled converter characteristics as described previously. The relay tripping times against distance to fault are plotted in Figures 4(e) and 4(f).

For both relays, when the "strong" VSC1 is used (providing a balanced fault response), their responses are severely compromised. In many cases there is a complete lack of response or a significant delay in tripping. This suggests that converters providing balanced responses to any unbalanced fault conditions may result in serious problems for protection if such converters provide the majority of the current for such faults.

When the system is supplied by "weak" VSC2, the performance of relay 1 appears acceptable. However relay 2 does not detect the presence of fault in any of the tests. 


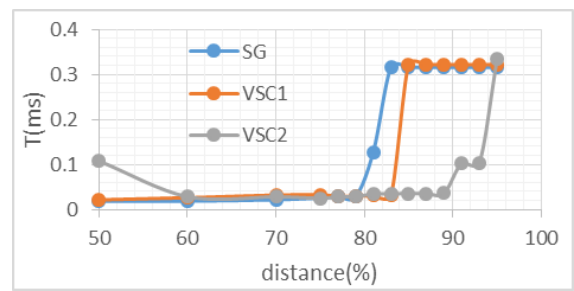

(a) Relay 1 : A-B-C faults

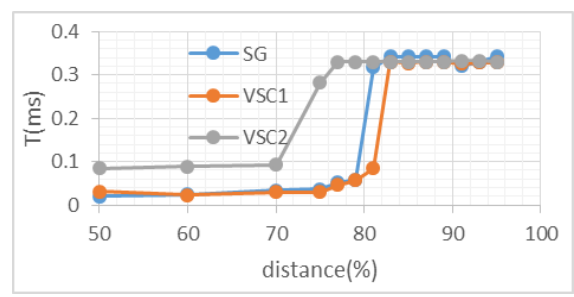

(b) Relay 2 : A-B-C faults

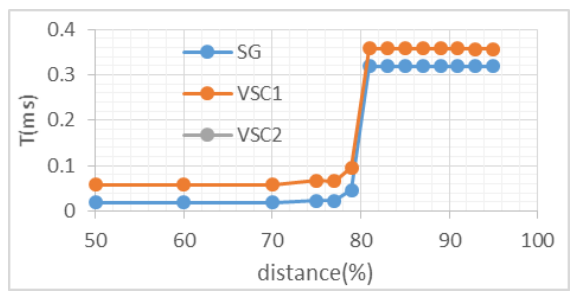

(c) Relay 1 : A-B faults

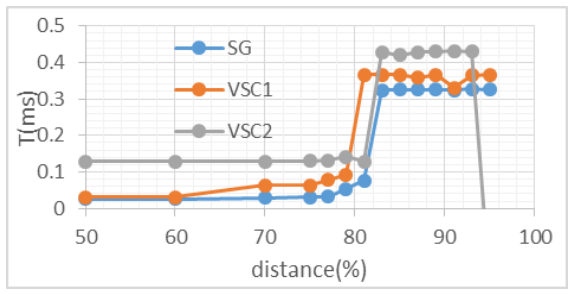

(d) Relay 2 : A-B faults

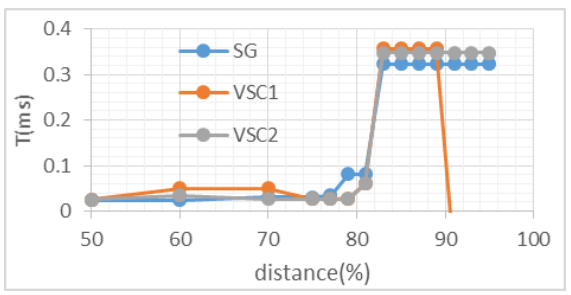

(e) Relay 1 : A-E faults

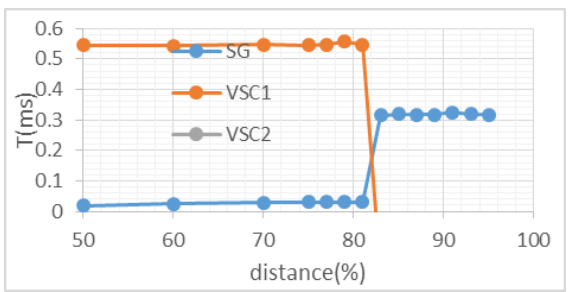

(f) Relay 2 : A-E faults

Figure 4 Relay tripping time against distance of the faults

\section{Conclusions and Future work}

This paper has illustrated how converter-interfaced energy sources respond very differently to network faults when compared to synchronous machines and that these differences in responses could lead to network protection problems in the future, where converter-interfaced sources may proliferate. A wide range of fault scenarios, using both models of synchronous machines and a configurable converter-interfaced source model, have been studied and the results show that, potentially, there are several areas of concern associated with the protection of future systems. However, further investigations are required. The results presented in this paper are based on dynamic models of power systems using both a protection relay model and an actual device. In order to have further confidence in the findings presented in this paper, future work, involving a wider range of scenarios, including more actual relay devices, and consisting of more comprehensive studies of "mixed" converter/synchronous machine source "mixes", is necessary.

\section{References}

[1] “UK Future Energy Scenarios 2014.” National Grid, 2014. Available http://www2.nationalgrid.com/UK/Industryinformation/Future-of-Energy/Future-Energy-Scenarios/

[2] H. Urdal, R. Ierna, J. Zhu, C. Ivanov, A. Dahresobh, and D. Rostom, "System strength considerations in a converter dominated power system," IET Renewable Power Generation, vol. 9, no. 1, pp. 10-17, 2015.

[3]"Electricity Ten Year Statement 2014." National Grid, 2014. Available

http://www2.nationalgrid.com/UK/Industryinformation/Future-of-Energy/Electricity-Ten-Year$\underline{\text { Statement/ }}$
[4]"Network Code on Requirements for Grid Connection applicable to all Generators." ENTSO-E, Mar-2013. Available at: http://networkcodes.entsoe.eu/wpcontent/uploads/2013/08/130308_Final_Version_NC_Rf G1.pdf

[5]"Network Code on HVDC Connections," ENTSO-E, 30Apr-2014. Available at: https://www.entsoe.eu/Documents/Network $\% 20$ codes $\% 2$ 0documents/NC\%20HVDC/140430-NC\%20HVDC.pdf

[6] R. Li, C. D. Booth, A. Dysko, A. J. Roscoe, and J. Zhu, "Development of models to study VSC response to AC system faults and the potential impact on network protection," in Power Engineering Conference (UPEC), 2014 49th International Universities, 2014, pp. 1-6.

[7] R. Li, C. D. Booth, A. Dysko, A. J. Roscoe, J. Zhu, and H. Helge, "Protection challenges in future converter dominated power systems," in Protection, Automation \& Control World Conference 2015, 2015, pp. 1-6.

[8] R. Li, C. D. Booth, A. Dysko, A. J. Roscoe, H. Urdal, and J. Zhu, "Protection challenges in future converter dominated power systems: demonstration through simulation and hardware tests," in International conference on Renewable Power Generation 2015, 2015, pp. 1-6.

[9] J. Yang, J. E. Fletcher, and J. O'Reilly, "Short-Circuit and Ground Fault Analyses and Location in VSC-Based DC Network Cables," IEEE Transactions on Industrial Electronics, vol. 59, no. 10, pp. 3827-3837, Oct. 2012.

[10] J. Keller and B. Kroposki, "Understanding Fault Characteristics of Inverter-Based Distributed Energy Resources," National Renewable Energy Laboratory (NREL), NREL/TP-550-46698, 2010.

[11] K. I. Jennett, C. D. Booth, F. Coffele, and A. J. Roscoe, "Investigation of the sympathetic tripping problem in power systems with large penetrations of distributed generation," IET Generation, Transmission Distribution, vol. 9, no. 4, pp. 379-385, 2015.

[12] J. Fortmann, R. Pfeiffer, E. Haesen, F. van Hulle, F. Martin, H. Urdal, and S. Wachtel, "Fault-ride-through 
requirements for wind power plants in the ENTSO-E network code on requirements for generators," IET Renewable Power Generation, vol. 9, no. 1, pp. 18-24, 2015.

[13] “The Grid Code.” National Grid, 31-Mar-2014. Available at: $\quad$ http://www2.nationalgrid.com/UK/Industryinformation/Electricity-codes/Grid-Code/

[14] A. Dysko, J. R. McDonald, G. M. Burt, J. Goody, and B. Gwyn, "Integrated Modelling Environment: a platform for dynamic protection modelling and advanced functionality," in 1999 IEEE Transmission and Distribution Conference, 1999, vol. 1, pp. 406-411 vol.1. 